\title{
Structural Studies of Selected DSPC-Surfactant Model Systems of Biological Membranes
}

\author{
K. Szpotkowski ${ }^{a}$, M. $\operatorname{KozAK}^{a, *}$, A. $\operatorname{KozAK}^{b}$, R. Zieliński ${ }^{c}$, \\ D. WIECZOREK ${ }^{c}$ AND S. JURGA ${ }^{a}$ \\ ${ }^{a}$ Department of Macromolecular Physics, Faculty of Physics, A. Mickiewicz University \\ Umultowska 85, 61-614 Poznań, Poland \\ ${ }^{b}$ Department of Water Protection, Faculty of Biology, A. Mickiewicz University \\ Umultowska 89, 61-614 Poznań, Poland \\ ${ }^{c}$ Department of Technology and Environmental Protection, Faculty of Commodity Science \\ Poznań University of Economics, al. Niepodlegości 10, 61-875 Poznań, Poland
}

\begin{abstract}
Fourier transform infrared spectroscopy was used to analyse the influence of a cationic surfactant from the group of morpholine derivatives on the conformational dynamics of $\mathrm{CH}_{2}$ group in acyl chain of DSPC. The presence of the surfactant causes a decrease in the DSPC phase transition temperature. This result suggests that the surfactant interactions with phospholipid molecules disturb the lipid layers. The Fourier transform infrared measurements were supplemented with tests of the environmental toxicity of the surfactant used.
\end{abstract}

PACS numbers: 33.20.Ea, 47.55.dk, 87.14.Cc, 87.16.D-

\section{Introduction}

Functioning of all biological systems (cell organelles, cells, or whole organisms) is strictly dependent on the presence and structure of the cell membranes. The main substances forming the cell membranes are lipids, and among them phosphocholine derivatives [1]. The membranes show amphiphilic properties determining their ability to self-organisation and formation of unique lamellar structures. The temperature of the phase transition in phospholipids depends on the length of the fatty acid chains [2-4]. Fully hydrated 1,2-distearoyl-sn-glycero-3-phosphocholine (DSPC) shows two phase transitions: the pretransition $\left(L_{\beta}^{\prime} \rightarrow P_{\beta}^{\prime}\right)$ at $321.3 \mathrm{~K}\left(325.7 \mathrm{~K}\right.$ in $\left.\mathrm{D}_{2} \mathrm{O}\right)$ and the main transition $\left(P_{\beta}^{\prime} \rightarrow L_{\alpha}\right)$ at $326.5 \mathrm{~K}(328.5 \mathrm{~K}$ in $\left.\mathrm{D}_{2} \mathrm{O}\right)[5]$.

The phospholipids/surfactants systems in water have been recently intensely studied in investigation of phospholipid membranes structure and interactions, drug delivery systems and in many other biological and medical applications $[6,7]$. In aqueous solutions of ionic surfactants their molecules can exist in the monomeric form as long as the surfactant concentration is lower than the critical micelle concentration (CMC). At concentrations higher than the value of CMC they can be in the micellar or in a variety of lyotropic liquid crystalline phases being in equilibrium with monomers $[8,9]$. Since surfac-

* corresponding author; e-mail: mkozak@amu.edu.pl tants can form not only spherical micelles, bilayer membranes ("lamellae") or liposome structures, but also some of them can be used as simple models of biological cells. Therefore the interactions of biological membranes with surfactants seem to be very important in evaluation of the structure of natural systems.

In this work we report results of our experiments with 3 -( $N$-tetradecylmorpholine)-1-propansulfonate (zwitterionic surfactant with the sulfobetaine structure, abbreviated as $\mathrm{S}_{3} \mathrm{C}_{14}$ ). It is a newly synthesised compound being a sulfonate analogue of classical zwitterionic surfactants possessing a betaine structure. The CMC value for this surfactant is $0.52 \mathrm{mM}$ (or $0.02 \%$ ) at $298 \mathrm{~K}$ as determined by surface tension measurements [10].

The study was undertaken to establish the effect of zwitterionic surfactant $\mathrm{S}_{3} \mathrm{C}_{14}$ on the stability of the structural phases formed by DSPC in water solutions.

\section{Materials and methods}

\subsection{Sample preparation}

The phospholipid 1,2-distearoyl-sn-glycero-3-phosphocholine was obtained from Avanti Polar Lipids. The homogeneous $10 \%$ solutions of DSPC (in $\left.20 \mathrm{mM} \mathrm{K} \mathrm{HPO}_{4} / \mathrm{D}_{2} \mathrm{O}\right)$ and $0.1,0.5,1$, and $5 \% \mathrm{~S}_{3} \mathrm{C}_{14}$ surfactant/DSPC suspensions were prepared by the cyclic sonification at $340 \mathrm{~K}$ for $30 \mathrm{~min}$ and cooling at $278 \mathrm{~K} . \mathrm{D}_{2} \mathrm{O}$ was used as a solvent in preparation of the DSPC/surfactant mixture in order to better visualisation of the carbonyl region [11]. In all experiments $\mathrm{S}_{3} \mathrm{C}_{14}$ was used at concentrations higher than CMC. 


\subsection{FTIR spectroscopic measurements}

Fourier transform infrared (FTIR) spectra of DSPC solutions in the temperature range from 288 to $323 \mathrm{~K}$ were obtained using BRUKER IFS 66 FTIR-RAMAN spectrometer (Bruker). The spectrometer was equipped with a Globar IR source, KBr beam splitter, DLATGS detector with $\mathrm{KBr}$ window and SPECAC Variable Temperature Cell. Phospholipid solutions of $20 \mu \mathrm{l}$ volume were placed between KRS-5 windows with $0.2 \mathrm{~mm}$ teflon spacer and incubated for $15 \mathrm{~min}$ at a given temperature before starting the experiment. For each spectrum 128 scans in the spectral range $4000-600 \mathrm{~cm}^{-1}$ were collected with the resolution of $1 \mathrm{~cm}^{-1}$. The spectroscopic measurements of the pure DSPC solutions and $\mathrm{DSPC} / \mathrm{S}_{3} \mathrm{C}_{14}$ systems were performed in the range 275 $345 \mathrm{~K}$.

\subsection{Toxicity tests}

The model water organism Scenedesmus communis was cultured on the medium Chu-10 [12] (40 mg/l $\mathrm{Ca}\left(\mathrm{NO}_{3}\right)_{2}, 10 \mathrm{mg} / 1 \mathrm{~K}_{2} \mathrm{HPO}_{4}, 25 \mathrm{mg} / \mathrm{l} \mathrm{MgSO}_{4}, 25 \mathrm{mg} / \mathrm{l}$ $\mathrm{Na}_{2} \mathrm{SiO}_{3}, 20 \mathrm{mg} / \mathrm{l} \mathrm{Na}_{2} \mathrm{CO}_{3}, 3 \mathrm{mg} / \mathrm{l}$ of iron citrate, $0.6 \mathrm{mg} / \mathrm{l} \mathrm{H}_{3} \mathrm{BO}_{4}, 0.4 \mathrm{mg} / \mathrm{l} \mathrm{MnCl}_{2}, 0.05 \mathrm{mg} / \mathrm{l} \mathrm{ZnSO}$, $0.05 \mathrm{mg} / \mathrm{dm}_{3} \mathrm{CuSO}_{4}$, and $\left.0.02 \mathrm{mg} / \mathrm{l}\left(\mathrm{NH}_{4}\right)_{2} \mathrm{MoO}_{4}\right)$. $200 \mathrm{ml}$ of the medium was placed in conical flasks and inoculated with $2 \mathrm{ml}$ of the suspension of Scenedesmus. The concentration of Scenedesmus communis cells in the initial culture was from 3000 to 4000 cells $/ \mathrm{ml}$. The culture was grown for 11 days at $295 \mathrm{~K}$ under artificial illumination of $2900 \mathrm{~lx}$. The concentration of cells was controlled every day of the culture growth in a $2 \mathrm{ml}$ sample, which was fixed by Lugol fluid and analysed in a Buerker chamber under a microscope.

\section{Results and discussion}

The FTIR results are presented in Figs. 1-3 as a function of temperature. The temperature changes in the wave numbers of the maxima of the bands corresponding to $\nu_{\text {as }} \mathrm{CH}_{2}\left(\approx 2917 \mathrm{~cm}^{-1}\right)$ and $\nu_{\mathrm{s}} \mathrm{CH}_{2}\left(\approx 2850 \mathrm{~cm}^{-1}\right)$ can be used for determination of the temperature of the main phase transition $\left(T_{\mathrm{m}}\right)$, from the gel to the liquid crystal phase [2]. The gel phase is characterised by a high degree of packing thanks to the trans conformers and for this phase the $\nu_{\mathrm{as}} \mathrm{CH}_{2}$ and $\nu_{\mathrm{s}} \mathrm{CH}_{2}$ vibrations are characterised by lower values of wave numbers. Increasing temperature of the system induces formation of the gauche conformers whose presence reduces the strength of interaction between the alkyl chains of phospholipids. This reduction is manifested as an increase in the wave number values [3]. Figure 1 presents the positions of the $\nu_{\text {as }} \mathrm{CH}_{2}$ and $\nu_{\mathrm{s}} \mathrm{CH}_{2}$ bands for pure DSPC and the DSPC $/ \mathrm{S}_{3} \mathrm{C}_{14}$ systems. The point of the main phase transition for pure DSPC is at $329 \mathrm{~K}$, which is consistent with literature data [5]. Also the shifts of symmetric methylene $\mathrm{CH}_{2}$ stretching modes $\nu_{\mathrm{s}}$ from 2850.4 to $2853.3 \mathrm{~cm}^{-1}$ and antisymmetric $\mathrm{CH}_{2}$ stretching modes $\nu_{\text {as }}$ from 2918.3 to $2922.7 \mathrm{~cm}^{-1}$ (Fig. 2) in the vicinity of the main transition are in good agreement with the data obtained by Huffman et al. [13]. For DSPC/0.1\% $\mathrm{S}_{3} \mathrm{C}_{14}$ system, the shifts of the bands from 2850.4 to $2853.4 \mathrm{~cm}^{-1}$ and from 2919.2 to $2923.0 \mathrm{~cm}^{-1}$, characteristic of the main transition, were noted for $\nu_{\mathrm{s}} \mathrm{CH}_{2}$ and $\nu_{\mathrm{ss}} \mathrm{CH}_{2}$, respectively. The analogous shifts of the bands of the symmetric (from 2850.3 to $2852.8 \mathrm{~cm}^{-1}$ ) and antisymmetric (from 2919.0 to $2922.7 \mathrm{~cm}^{-1}$ ) methylene $\mathrm{CH}_{2}$ stretching modes were also observed for DSPC $/ 0.5 \% \mathrm{~S}_{3} \mathrm{C}_{14}$ and DSPC $/ 1 \% \mathrm{~S}_{3} \mathrm{C}_{14}$. For the DSPC $/ 5 \% \mathrm{~S}_{3} \mathrm{C}_{14}$ system the antisymmetric stretching band was shifted from 2918.9 to $2922.6 \mathrm{~cm}^{-1}$ and the symmetric stretching band was displaced from 2850.7 to $2853.0 \mathrm{~cm}^{-1}$.

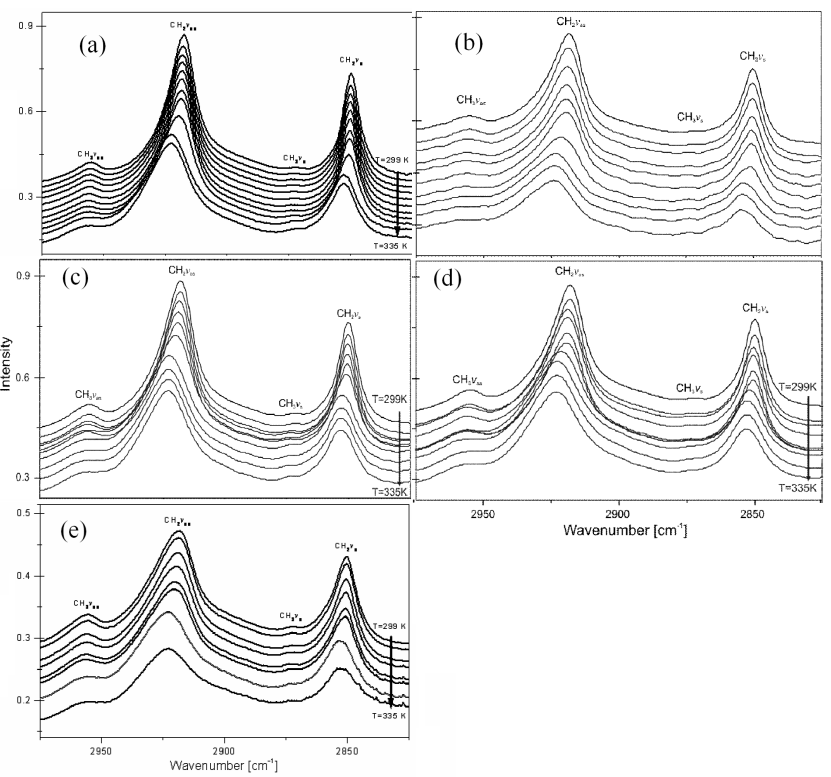

Fig. 1. FTIR spectra recorded for $10 \% \operatorname{DSPC}(\mathrm{a}), 10 \%$ DSPC $/ 0.1 \% \quad \mathrm{~S}_{3} \mathrm{C}_{14}$ (b), $10 \% \quad \mathrm{DSPC} / 0.5 \% \quad \mathrm{~S}_{3} \mathrm{C}_{14}$ (c), $10 \% \mathrm{DSPC} / 1 \% \mathrm{~S}_{3} \mathrm{C}_{14}(\mathrm{~d})$, and $10 \% \mathrm{DSPC} / 5 \% \mathrm{~S}_{3} \mathrm{C}_{14}$ (e), systems.

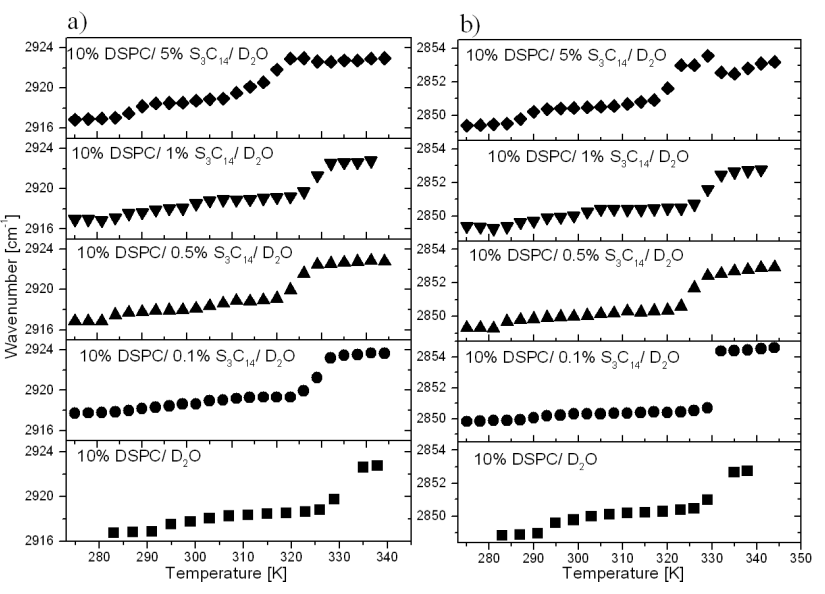

Fig. 2. Temperature variation of the frequency of the $\mathrm{CH}_{2}$ asymmetric (a) and symmetric (b) stretching modes of DSPC liposomes in the absence and presence of $\mathrm{S}_{3} \mathrm{C}_{14}$ surfactant. 


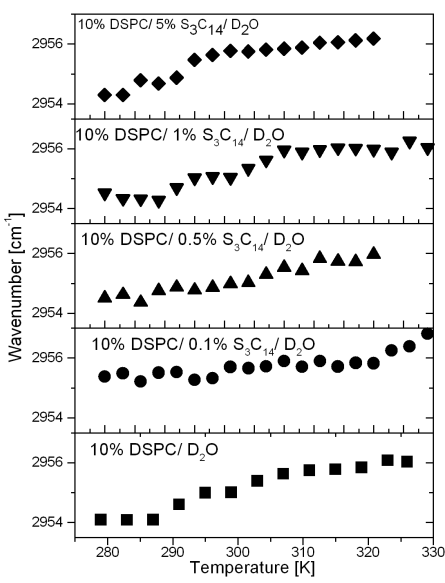

Fig. 3. Temperature dependence of frequency changes at the $\mathrm{CH}_{3}$ asymmetric modes for pure DSPC and for DSPC liposomes containing $\mathrm{S}_{3} \mathrm{C}_{14}$ surfactant.

Introduction of the surfactant to the system results in a decrease in the temperature of the main phase transition, probably as a result of the surfactant molecules grafting into the phospholipid bilayer. The surfactant molecules weaken the interchain interactions in the bilayer and induce the formation of the gauche conformers of alkyl chains. Moreover, depending on the surfactant concentration, the temperature range of the phase transition is broadened. This fact can be caused by a slower isomerisation of the chains related to the weakening of the interchain interactions [14-16]. The main phase transition point ( $\left.T_{\text {onset }}\right)$, estimated on the basis of the $\mathrm{CH}_{2}$ stretching modes is shifted to 328 and $324 \mathrm{~K}$ for DSPC $/ 0.1 \% \mathrm{~S}_{3} \mathrm{C}_{14}$ and DSPC $/ 0.5 \% \mathrm{~S}_{3} \mathrm{C}_{14}$ systems, respectively. Incorporation of $1 \%$ of $\mathrm{S}_{3} \mathrm{C}_{14}$ shifted the main phase transition temperature to $326 \mathrm{~K}$. Further addition of the surfactant $\mathrm{S}_{3} \mathrm{C}_{14}$ results in a shift of the main phase transition even to $314 \mathrm{~K}$ for $\mathrm{DSPC} / 5 \% \mathrm{~S}_{3} \mathrm{C}_{14}$ system.

Analysis of the changes in the wave numbers of the band assigned to the vibrations of the terminal $\mathrm{CH}_{3}$ group of alkyl chains provides the information on the conformational changes at the centre of the phospholipid bilayer [17]. The temperature dependence of the wave number of the asymmetric stretching vibrations of $\mathrm{CH}_{3}$ group is shown in Fig. 3. In the spectra of pure DSPC the wave number continuously increases with temperature, which suggests increasing freedom of the $\mathrm{CH}_{3}$ group vibrations. In the spectra of the systems DSPC/surfactant, the wave number undergoes jumpwise changes depending on the surfactant concentration. After the main phase transition (in the gel phase), the frequencies of the asymmetric stretching vibrations of $\mathrm{CH}_{3}$ group of the DSPC $/ \mathrm{S}_{3} \mathrm{C}_{14}$ systems are higher than those in pure DSPC, indicating that the interactions with the surfactant (or inclusion into bilayers) increases the librational freedom of the acyl chains of DSPC in the central area of the bilayer.

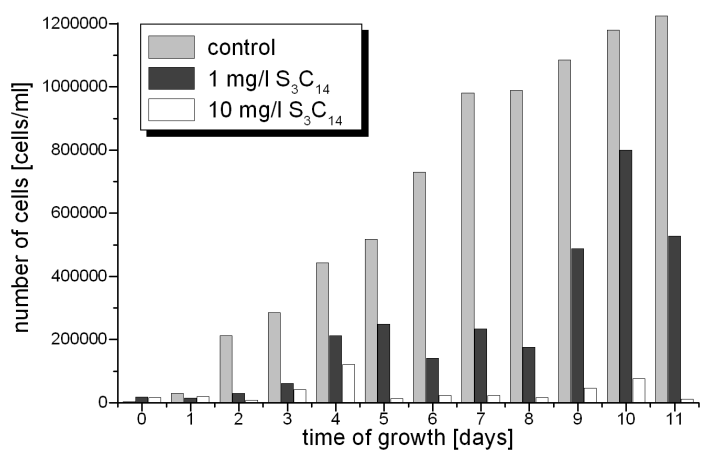

Fig. 4. The effect of the surfactant $\mathrm{S}_{3} \mathrm{C}_{14}$ concentration on the growth of the Scenedesmus communis.

Figure 4 illustrates the effect of the surfactant on the growth of the model aquatic organism Scenedesmus communis. The cultures containing the surfactant in the medium were observed to show a significant inhibition of growth of the organisms studied relative to that in the reference culture (without the surfactant). The surfactant $\mathrm{S}_{3} \mathrm{C}_{14}$ had a detectable inhibitory effect on the growth of the organisms studied already at the concentration of $1 \mathrm{mg} / \mathrm{l}$. The total inhibition of growth of the algae was observed in the cultures growing in the medium containing $10 \mathrm{mg} / \mathrm{l}$ of the surfactant.

\section{Conclusions}

- Surfactants built into the phosholipids bilayer introduce the conformational disorder, which causes a decrease in the phase transition temperature of DSPC;

- The differences in the parameters characterising the main phase transitions in the systems DSPCsurfactant, can be related to the surfactant toxicity effect on the algae studied. The toxic effect of the surfactant studied is supposed to be related to disturbances in the cell membrane structure.

\section{Acknowledgments}

The research was supported in part by the intercollegiate research grant (AE-UAM, No. 51200 068). The authors would like to thanks Rectors of A. Mickiewicz University (Poznań, Poland) as well as Poznań University of Economics for generous support.

\section{References}

[1] Lipid Bilayers - Structure and Interactions, Eds. J. Katsaras, T. Gutberlet, Springer-Verlag, Berlin 2001.

[2] F. Severcan, S. Bayari, D. Karahan, J. Mol. Struct. 480-481, 413 (1999). 
[3] F. Severcan, I. Sahin, N. Kazani, Biochim. Biophys. Acta 1668, 215 (2005).

[4] R. Koynova, A. Koumanov, B. Tenchov, Biochim. Biophys. Acta 1285, 101 (1996).

[5] H. Matsuki, H. Okuno, F. Sakano, M. Kusube, S. Kaneshina, Biochim. Biophys. Acta 1712, 92 (2005).

[6] S. Svenson, Curr. Opin. Colloid Interface Sci. 9, 201 (2004).

[7] J.Y. Fang, T.L. Hwang, Y.L. Huang, Curr. Nanosci. 2, 55 (2006).

[8] D. Myers, Surfactant Science and Technology, Wiley, Hoboken, NJ 2006.

[9] C.A. Miller, P. Neogi, Interfacial Phenomena. Equilibrium and Dynamic Effects, 2nd ed., CRC Press, Boca Raton 2008.
[10] D. Wieczorek, Ph.D. Thesis, Poznań, 2008 (in Polish).

[11] S.B. Diaz, F. Amalfa, A.C. Biondi de López, E.A. Disalvo, Langmuir 15, 5179 (1999).

[12] S.P. Chu, J. Ecology 30, 284 (1942).

[13] S.W. Huffman, S. Schlücker, I.W. Levin, Chem. Phys. Lipids 130, 167 (2004).

[14] P. Wolfangel, R. Lehnert, H.H. Meyer, K. Müller, Phys. Chem. Chem. Phys. 1, 4833 (1999).

[15] F. Severcan, N. Kazanci, F. Zorlu, Biosci. Rep. 20, 177 (2000).

[16] F. Severcan, Biosci. Rep. 17, 231 (1997).

[17] N. Toyran, F. Severcan, Chem. Phys. Lipids 123, 165 (2003). 